$$
\text { "szeredi" — 2007/8/9 — 14:01 — page } 29-\# 1
$$

\title{
Teaching polygons in the secondary school: a four country comparative study
}

\author{
Éva SzEREdI and JUdiT TöRÖK
}

\begin{abstract}
This study presents the analysis of four sequences of videotaped lessons on polygons in lower secondary schools (grades 7 and 8) taught by four different teachers in four different countries (Belgium, Flanders, England, Hungary and Spain). Our study is a part of the METE project (Mathematics Educational Traditions in Europe). The aims and methodology of the project are described briefly in the introduction. In the next section of this paper we describe various perspectives on teaching and learning polygons which were derived from the literature, concerning the objectives, conceptual aspects and didactic tools of the topic. The next two sections introduce the main outcomes of our study, a quantitative analysis of the collected data and a qualitative description linked to the perspectives on teaching polygons. We conclude by discussing some principal ideas related to the theoretical and educational significance of this research work.
\end{abstract}

Key words and phrases: comparative studies on mathematics education in different countries, comprehensive works on geometry and the teaching of geometry.

ZDM Subject Classification: D10, G10.

\section{Introduction}

The METE project

METE was a two year (2003-2004) project founded by the European Union with participants from five European countries: England, Belgium, Finland, Spain and Hungary. These five countries represent quite well the different mathematics 


$$
\text { "szeredi" — 2007/8/9 — 14:01 — page 30 — \#2 }
$$

teaching traditions of Europe and a variation of students' attainment in other international comparisons like TIMMS and PISA.

The aim of the project was a comparative study of the different ways in which mathematics is conceptualized and the different methods teachers use to present mathematics to learners of the age group 10-14.

We adopted a socio-constructivist perspective on learning and teaching acknowledging that learning is a social construction mediated by teaching. Understanding learners' performances requires a knowledge of the socio-cultural setting in which the learning takes place. So we focused our study on the analysis of learning-in-context.

We collected data from live observations and from series of videotaped lessons on four standard topics, 3-5 lessons in each country in each topic (percentages for class 5 or 6 , polygons for class 5 or 6 , linear equations for class 7 or 8 and polygons for class 7 or 8 ) and developed instruments for both qualitative and quantitative analysis $[1,2]$.

We created a coding scheme for the quantitative analysis with four main categories (each divided into several subcategories): mathematical focus (conceptual, derivational, structural, procedural, efficiency, problem solving, reasoning), mathematical context (real world genuine data, real world fabricated data, not real world genuine data, not real world fabricated data), didactics (activating prior knowledge, exercising prior knowledge, explaining, sharing, exploring, coaching, assessing or evaluating, motivating, differentiation), materials used by the teacher and by the students (textbook, blackboard, games, manipulative, computer etc.).

We used a (Reusser type) lesson synthesis sheet for the qualitative analysis which contains a brief description of a lesson and two color-coded timelines, one for the pedagogic activities (theory or conceptual development, working on tasks, reporting solutions to tasks, introducing an activity, homework related activities, task-related management, non task-related management), the other for social activities (whole class, group, paired, individual).

The English team undertook the elaboration of the scientific background of both teaching equations and a general comparison and also the analysis of the videotaped lessons on equations and the analysis of the overall data. The Belgian team worked on the teaching percentages, the Spanish team on primary polygons, the Hungarian on secondary polygons. The present paper is about the teaching secondary polygons, the topic analyzed by the Hungarian team.

The background, the tools and the main outcomes of the research are described in details in an other paper [14]. 


$$
\text { "szeredi" — 2007/8/9 — 14:01 — page } 31-\# 3
$$

Although is was not the aim of the project to evaluate the efficiency of mathematics teaching in these countries, you can find some references to the PISA and TIMMS results in relation with the findings of our project (Andrews, P., Sawyers, J.: Conditions for learning).

\section{A perspective on teaching and learning of polygons in lower secondary school}

\subsection{Objectives}

Objectives in teaching of polygons are strongly connected to the general aims of teaching of geometry.

Although there is a "strong disagreement about the aims, contents and methods for the teaching of geometry at various levels, from primary school to university" a set of possible aims are provided in a discussion document for an ICMI study [15].

- "To describe, understand and interpret the real world and its phenomena.

- To supply an example of axiomatic theory.

- To provide a rich and varied collection of problems and exercises for individual student activity.

- To train learners to make guesses, state conjectures, provide proofs and find out examples and counterexamples.

- To serve as a tool for other areas of mathematics.

- To enrich the public perception of mathematics."

This list is about geometry in general and about the whole range of geometry education from kindergarten to university. In this paper we try to focus on questions of teaching polygons in the lower secondary classes (grade 7-8). At that period this topic is a very important part of the curriculum in each of the participating countries and could supply many opportunities to the realization of all the above aims with the only exception of the axiomatic examples. How far these aims were attained in the videotaped lessons, were they present at all, we will discuss in more detail in our qualitative analysis.

There are several models of the cognitive development of the spatial thinking. Van Hieles worked out one such model. They found that the development of spatial thinking is not a continuous process but there are discrete stages, which depend more on the learning experiences than on the age of the children [8]. 


$$
\text { "szeredi" — 2007/8/9 — 14:01 — page } 32-\# 4
$$

0. level Visual - judges shapes by their appearance.

1. level Analysis - e.g. sees figures in terms of their components and discovers properties of a class of shapes.

2. level Informal deduction - e.g. logically interrelates previously discovered properties.

3. level Deduction - proves theorems deductively.

4. level Rigor - e.g. establishes theorems in different postulation systems.

Although further research found some elements of this model questionable, it is quite widely accepted as a basis for studies in this field. We will use it as a framework for our qualitative analysis as well.

\subsection{Conceptual aspects of polygons in upper primary and secondary} education

\subsubsection{Definitions and properties}

\section{Definitions}

The topic of polygons is appropriate for introducing the concept of definitions because it provides plenty of opportunities for developing our students on that area. Children at that age are normally able to work on the 1. and 2. van Hiele levels, what is necessary for this type of mental work. However, we have to be careful what to define precisely and what not, because in many cases the most basic concepts are the most difficult to define.

For example at this age we can take the idea of polygons already established. Students can distinguish simple polygons from non-polygons but they are not at all ready for a precise definition of a polygon in general, because it is too complicated.

With the special triangles and special quadrilaterals the situation is just the opposite. If we take the definition of a polygon for granted, then the students can easily define these special polygons. Apart from their definitions they have plenty of interesting properties, and provide very good opportunities for understanding the difference between the definition of a shape and other true statements about the - already defined - shape.

The topic is provides good opportunities for working with if/then statements, where the premises and the consequences are clearly separated and the logical relationships are clear. We come back to that in the didactic tools chapter. At 


$$
\text { "szeredi" — 2007/8/9 - 14:01 — page } 33 \text { — \#5 }
$$

the same time it provides important opportunities to show examples where the inverse statement is not true.

\section{Classifications}

Classification of the polygons raises quite a few problems. The children in many cases think about the special polygons in disjoint categories. For them, it generally is quite difficult to accept that a square is a special rectangle or a special rhombus and so on... The reason behind that may partly lie in the cognitive development of the students' spatial concepts, and partly in the methods teachers use in introducing these special quadrilaterals.

"... young children are taught by a "template" (visual prototype) approach to recognizing geometric patterns." [5]. It seems to us, that this template approach is quite all right when young children get acquainted with the simplest quadrilaterals, such as rectangles and squares. That is the natural way of children's thinking at the early - 0. or 1. - Van Hiele levels. So, quite evidently, that is the natural way for teaching as well. But according to Kay's research [10], it may well be wiser to start teaching the other types of polygons later, and in a more systematic way, by defining these as classes, given by certain properties. Squares and rectangles are very common shapes, which cannot be left out of the primary curriculum. But the names of other special quadrilaterals - like rhombus, parallelogram ... - probably are not so important.

Of course the children can (and probably should) come across these shapes earlier, work with them in many different kinds of activities, and their names may be mentioned as well. But as the main subject of study, these probably can come later. That idea corresponds well to the cognitive theory of the van Hieles. "Concepts implicitly understood at one level become explicitly understood at the next level." "At each level there appears in an extrinsic way that which was intrinsic at the preceding level. At the base level, figures were in fact also determined by their properties, but someone thinking at this level is not aware of these properties" [8].

Using Wenn diagrams can make these interfigural relationships even more plausible. They give much clearer picture of these relationships than diagrams with arrows.

\section{Symmetry}

Symmetries should play an important role in the geometry teaching. These are fundamental phenomena of the real world. And just because the children have plenty of (visual and non-visual) experience around them, symmetries can 


$$
\text { "szeredi" — 2007/8/9 — 14:01 — page } 34-\# 6
$$

be used very effectively in the teaching of geometry, and especially in the teaching of polygons.

If children understand the symmetry properties of the special polygons then classifying them becomes more natural. What is more, the other properties of these shapes can be derived easily from their symmetry property, so symmetries can be used quite conveniently in the classroom for clean and precise reasoning.

In this topic symmetry can work as a mnemotechnic as well. The problem with the teaching of polygons is that there are very many shapes and properties and names and it is very easy to get lost in the details. But it is enough to remember the symmetry-property of a shape, and all the other properties follow easily and naturally from this.

\subsubsection{Conceptual aspects of drawings (visual images)}

Drawings, pictures are important and helpful in teaching geometry. They help the students a lot in understanding and solving logically more complex tasks than in other areas of school mathematics. For some children who are otherwise weak in mathematics, but have good visual skills, these make it possible to be more successful in the geometry lessons. But, apart from these, drawings have their disadvantages. They are the source of several misconceptions in geometry teaching.

For example, when a triangle looks like an isosceles triangle, children take it for granted very easily, that it is an isosceles triangle even if it is just a matter of chance. This way, instead of helping the logical thinking, drawings become easily the origins of false reasoning.

Van Hiele's opinion (commented by Clemens and Battista) is, that for students, working on the 1. - descriptive/analytic level - "The image is not the basis for judgment, the network of relations is. Even if a figure was imperfectly drawn (or distorted on a computer screen) such students' thinking would not be swayed if they were assured it was the intention of the drawer to make all sides equal" [5].

When we get to reasoning in geometry the children for a long time are strongly depending on the pictures. That is all right as far as the picture is a support tool and not the basis of the reasoning. The reasoning has to be based on a network of relations and on logic.

Alsina et al. (1987) says that "two types of comprehension and modes of expression in the knowledge of geometric space can be differentiated: that which corresponds to geometric intuition, visual in nature and which is carried out in a 


$$
\text { "szeredi" — 2007/8/9 - 14:01 — page } 35-\# 7
$$

direct way (creative and subjective); and the association with logic, by its nature verbal and is carried out in a reflective manner (analytic and objective)."

We think that one of the crucial tasks of geometry teaching is to connect these two types of comprehension, so that visual images remain very important sources of intuition and creativity, but they have to be backed by analysis and logic. The 4. van Hiele level - the rigor - is achieved when reasoning is completely liberated from visuality.

\subsubsection{Proofs}

Why prove? - is a very important question, because the intention to convince someone (for example the student him/herself) is a crucial condition for proving something. A close consequence of this is that developing children in proving is only possible in a classroom atmosphere, where children are encouraged to discuss their own ideas.

The other key concept about proofs is establishing mathematical truth. "... as students construct mathematical meaning and build a network of knowledge in mathematics, the process by which they establish mathematical truth for themselves becomes vitally important" [5]. The same study claims that the unavoidable condition of becoming able to understand and provide proofs is that the students have already "developed those beliefs and schemes that motivate them and allow them to establish mathematical truths."

Piaget, van Hiele and other researchers agree that there are levels in the development of children's proof skills. Piaget thinks that these levels are basically depending on the age of the children. These are the ages of 7-8 through 11-12 when they begin trying to justify their results, and deductive reasoning only starts after that. According to van Hiele, proof skills are connected more to the level of mathematical thinking than to the age.

According both to Piaget and van Hiele models, the upper primary and lower secondary school age is crucial in the developing of proof skills, and at the same time it is too early for strictly formal proofs. That is why - although by proof the literature basically means formal proof - we would like to use the word in a more general sense. In the sequel we will use it as a synonym of establishing truth - in the process of teaching/learning - by argumentation and reasoning.

As a consequence of all these theoretical assumptions, at the primary and middle school ages we would like to emphasize two major elements in teaching proofs: 


$$
\text { "szeredi" — 2007/8/9 — 14:01 — page 36 — \#8 }
$$

- The first is the curiosity of children in questions like these: Is that true? Does it follow from something else? Does it verify something else? At the beginning these questions come from the teacher. After a while the children may become interested in them. That is the first step towards learning proving.

- The second is the establishment of some basic statements/theorems which are accepted and believed as truth by the children.

After these conditions are fulfilled simple deductions can come very naturally, and in a slow process students may get used to accept that not only experiments, but deductive reasoning may lead to true statements.

\subsection{Didactic tools}

\section{Methods of acquiring concepts and skills}

In connection with the methods the first and probably the most important question is the main aim of the teaching process. Where is the main emphasis in the lesson?

Is it

- on the details of the topic like definitions, properties, naming, signing, ...

- on developing geometric thinking

- on developing thinking

- on practical spatial and numerical skills

- on problem solving

- on exercising ...?

This emphasis has a great influence on choosing the methods. At the same time the same methods can play different roles during different lessons, depending on the central aim of them.

We classified the most relevant methods used in the classroom by different aspects on the lesson synthesis sheet and on the Didactics part of the Coding scheme. We measured the time spent in whole class activity, individual, group work or paired work. How much time was used for explaining, problem solving or questioning-sharing. We measured the number of episodes focused in exercising, exploring and reasoning, and the number of episodes with differentiation, motivation. 


$$
\text { "szeredi" — 2007/8/9 — 14:01 — page } 37 \text { — \#9 }
$$

\section{Structure}

The question of structuring the mathematical content is especially important in the geometry teaching. The structure of introducing new ideas and the structure of the problems and exercises are both relevant in the process of building up knowledge in students' minds.

We may add a lot to their understanding of geometry if we provide a learning environment which is full of connections, not only within one area but between different topics of geometry or between geometry and other parts of mathematics.

\section{Methods of reasoning}

In the process of establishing truth in the mathematics lessons teachers have several choices.

- The first is based on the authority of the teacher. We can call this sort of didactic tool demonstration. This is the case, when the teacher tells or shows something, and the children are supposed to listen and remember.

This method is a very important and natural way of learning, we get most of our knowledge this way. But this is not enough when we would like to teach thinking. George Pólya says that "for efficient learning, the learner should discover by himself as large a fraction of the material to be learned as feasible under the given circumstances" [12].

- The second method for establishing truth is the inductive way. That means experimenting, making conjectures, creating examples and counterexamples.

The difference is not just the more active participation of the children, but the presence of questions. This is an excellent way of developing thinking, but works only if the children are interested in the question and in the activity. In the first case the teacher presents the content and the child listens. In the second case the teacher asks questions and the children get the answer by experimenting and by discussion. Measuring can play a very important role in these activities, as it is an excellent tool for inductive activities.

- The third way is when the children reach the right answer by deduction.

\section{Materials used in the classroom}

Using materials in geometry teaching is unavoidable. At least rulers and compasses are used everywhere.

Using cardboard or solid models, cut-outs, geoboard, geosticks, everyday materials... makes the understanding of geometry easier, and makes the children more motivated. The role of these materials is in many aspects similar to the role 


$$
\text { "szeredi" — 2007/8/9 — 14:01 — page } 38 \text { — \#10 }
$$

of the drawings. They are mediators between reality and abstract concepts. Like the drawings they have advantages and - if not properly used - dangers in the teaching.

Computers are used more and more frequently. They are very good for nice demonstrations and excellent for geometrical investigations. Cabri or LOGO can provide fantastic experiences but only after the children mastered using the software. (If not, then the computer can take the attention from the mathematics and become an additional task.) But the computer should not be the substitute for the work with manipulatives and experimenting with real objects. Manipulatives, games, observing/investigating patterns, connections with real life, - all sort of real experiences - remain still very important in geometry teaching.

\section{Activities}

We classified and grouped the activities in the classroom by different aspects on the Reusser sheet and on the Didactics part of the Coding scheme as well. Some important kinds of activities were still left out. For example games happened in more than one case in the videotaped lessons. They fell in the category of whole class activity with motivation. They seem not to be very frequently used but effective ways of teaching and probably deserve more attention.

\section{Quantitative analysis}

Whenever we write for example about England, or about an English geometry lesson, we refer only to the videotaped lessons. We do not think that it is characteristic example of English teaching. The same is true of course about any of the other participating countries. At the same time we think that these lessons are good representatives of their countries.

This analysis is based on the categories of the LS (lesson synthesis sheet) and CS (coding scheeme) (Appendix II. and III., [14]).

\subsection{Social activity}

The next graph shows the distribution of time spent on different types of social activities for each country: 


$$
\text { "szeredi" — 2007/8/9 — 14:01 — page 39 — \#11 }
$$

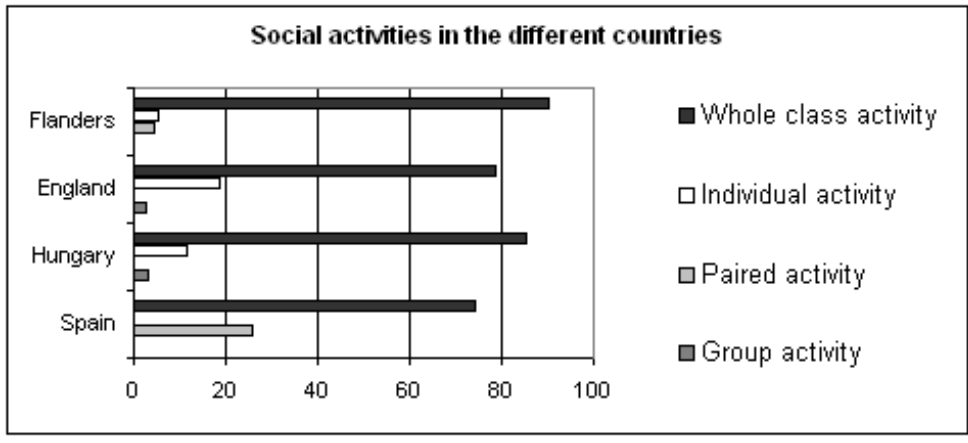

Whole class activities dominate in all of the countries (more than $70 \%$ of the time in each of them) especially in Flanders (90.3\%) and Hungary (85.1\%). No group activity was observed in Flanders and Spain and no paired activity in England and Hungary. There was no individual activity during the Spanish lessons.

\subsection{Pedagogic activity}

The next graph shows the distribution of time spent on the different pedagogic activities for each country:

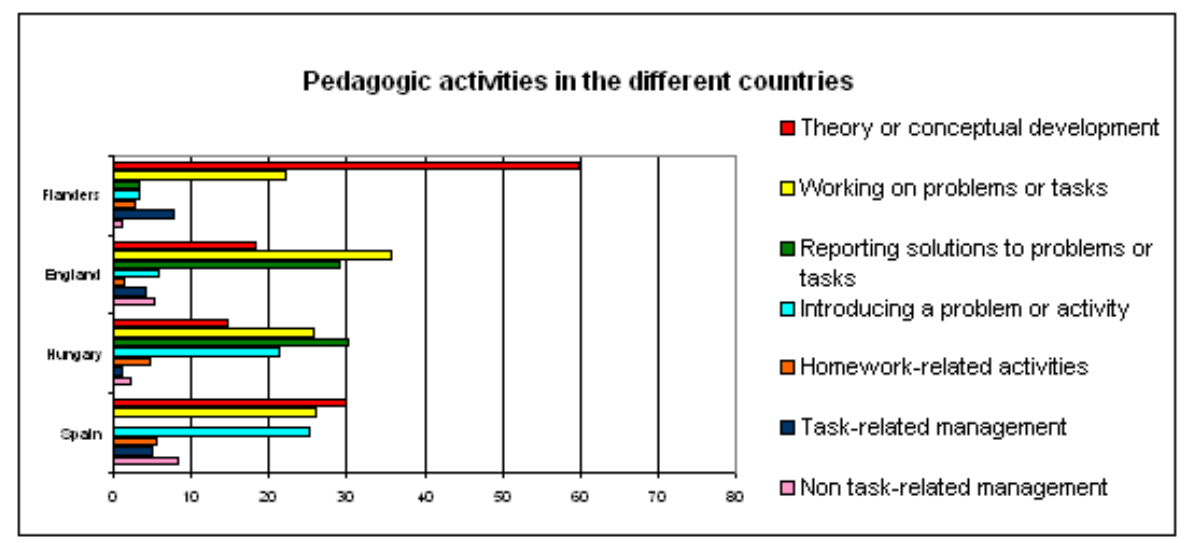

Theory or conceptual development is the dominant pedagogic activity in Flanders and Spain, while working on problems or tasks and reporting solutions in England and Hungary. The percentage of time spent with working on problems is 


$$
\text { "szeredi" — 2007/8/9 — 14:01 — page } 40-\# 12
$$

the highest in England and almost the same for the other three countries. Introducing problems or activities took considerable time in Hungary and Spain, while there was no reporting during the Spanish lessons and hardly any in Flanders.

\subsection{Mathematical focus}

The next figure shows the distribution of the foci for each country in terms of percenteges of all the episodes:

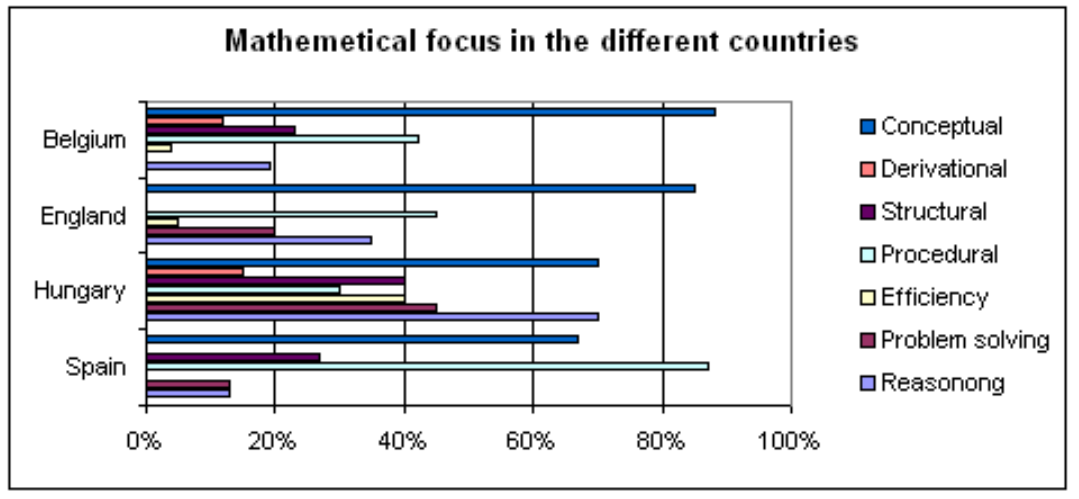

The percentages of episodes in which reasoning, problem solving, efficiency, structural or derivational aspects occurred are highest in Hungary. The percentage of procedural episodes is highest in Spain, while the percentage of conceptual episodes is highest in Belgium (and England). No episodes involving efficiency were observed in Spain, and no derivational episodes occurred in either England or Spain.

Conceptual episodes dominate in Belgium and England. The percentage of them is also quite high in Hungary and Spain, but in Hungary reasoning has the same measure while in Spain the ratio of procedural episodes is higher. Both in Belgium and England procedural is the second highest percentage. The third highest score is structural in Belgium and Spain, while in England and Hungary it is problem solving. Efficiency has a considerable measure only in Hungary.

\subsection{Mathematical context}

The next figure shows the distribution of the different contexts: 


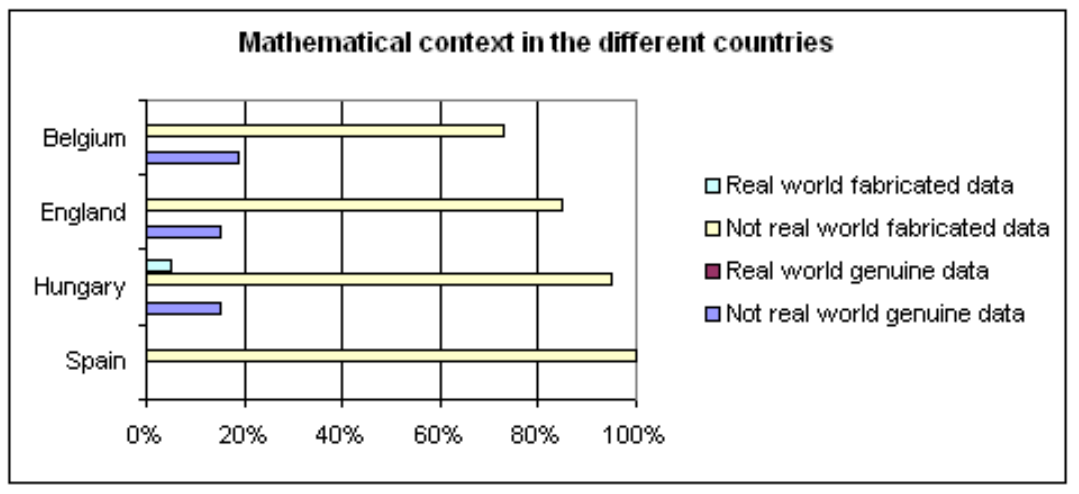

We can see that working with fabricated data not connected to real world is absolutely dominant in each of the countries, especially in Spain where this context is exclusive. The lowest percentage of episodes with such data was observed in Belgium, but even there it characterized almost three quarters of the episodes (73\%). Working with genuine data (not real world) occurred almost in the same proportion in Belgium (19\%), England and Hungary (15-15\%). Real world fabricated data was observed only in one episode (during the second Hungarian lesson), while no episodes were observed with real world genuine data in any of the countries.

\subsection{Didactics}

The next figure shows the distribution of didactic tools:

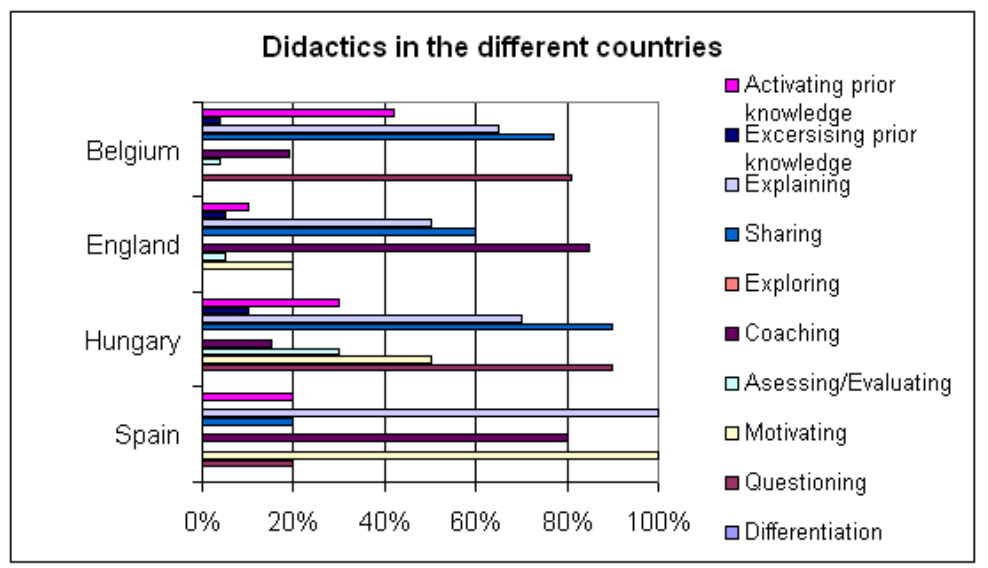




$$
\text { "szeredi" — 2007/8/9 — 14:01 — page } 42 \text { — \#14 }
$$

We can see that in Belgium questioning, sharing and explaining are the main didactical tools, activating prior knowledge plays also an important role, there is some coaching, while exercising prior knowledge and assessing occurred only in one episode in one lesson.

In England coaching is dominant, followed by sharing and explaining. Motivating was observed in one episode of the first and three episodes of the third lesson. Activating prior knowledge occurred in two episodes (one in the first and one in the second lesson), exercising prior knowledge and assessing in one episode each.

In Hungary questioning and sharing were the main tools with high proportion of explaining. Half of the episodes contained motivating and about the third of them contained assessing. There were occasional episodes with coaching and exercising prior knowledge.

In Spain explaining and motivating characterized all of the episodes. Coaching also occurred in the great majority of them. Activating prior knowledge, sharing and questioning all got $20 \%$.

The next table gives us an overall picture of the codes for mathematical focus, mathematical context and didactics:

\begin{tabular}{|l|l|c|c|c|c|c|c|}
\hline & & Belgium & England & Hungary & Spain & Total & Average \\
\hline \multirow{5}{*}{ Math. focus } & Nr. of episodes & 26 & 20 & 20 & 15 & 81 & 20.25 \\
& Conceptual & 23 & 17 & 14 & 10 & 64 & 16 \\
& Derivational & 3 & 0 & 3 & 0 & 6 & 1.5 \\
& Structural & 6 & 0 & 8 & 4 & 18 & 4.5 \\
& Procedural & 11 & 9 & 6 & 13 & 39 & 9.75 \\
& Efficiency & 1 & 1 & 8 & 0 & 10 & 2.5 \\
& Problem solving & 0 & 4 & 9 & 2 & 15 & 3.75 \\
& Reasoning & 5 & 7 & 14 & 2 & 28 & 7 \\
\hline Math. context & Real-fabricated & 0 & 0 & 1 & 0 & 1 & 0.25 \\
& Not real-fabricated & 19 & 17 & 19 & 15 & 70 & 17.5 \\
& Real-genuine & 0 & 0 & 0 & 0 & 0 & 0 \\
& Not real-genuine & 5 & 3 & 3 & 0 & 11 & 2.75 \\
\hline Didactics & Activating... & 11 & 2 & 6 & 3 & 22 & 5.5 \\
& Exercising... & 1 & 1 & 2 & 0 & 4 & 1 \\
& Explaining & 17 & 10 & 14 & 15 & 56 & 14 \\
& Sharing & 20 & 12 & 18 & 3 & 53 & 13.25 \\
& Exploring & 0 & 0 & 0 & 0 & 0 & 0 \\
& Coaching & 5 & 17 & 3 & 12 & 37 & 9.25 \\
& Assessing & 1 & 1 & 6 & 0 & 8 & 2 \\
\hline
\end{tabular}




$$
\text { "szeredi" — 2007/8/9 — 14:01 — page } 43 \text { — \#15 }
$$

Teaching polygons in the secondary school: a four country comparative study 43

\begin{tabular}{|l|l|c|c|c|c|c|c|}
\hline & & Belgium & England & Hungary & Spain & Total & Average \\
\hline Didactics & Motivating & 0 & 4 & 10 & 15 & 29 & 7.25 \\
& Questioning & 21 & 0 & 18 & 3 & 42 & 10.5 \\
& Differentiation & 0 & 0 & 0 & 0 & 0 & 0 \\
\hline
\end{tabular}

\section{Qualitative analysis}

We created a "composite lesson" on secondary polygons which is a kind of "average lesson", derived from all the lessons on polygons in all the four countries. In the case of the categories of CS the "composite lesson" is characterized by the ratio of the number of episodes in which the category was scored and the total number of episodes. For example:

We can see in the above table that the number of all episodes of all the lessons on polygons in the four countries was 81. Among these the number of episodes with conceptual focus was 64 . So we characterize the composite lesson in the case of "conceptual" category with $64 / 81=0.79$, so with $79 \%$.

In the case of the categories of LS the composite lesson is characterized by the percentages of time during which a certain activity was observed compared with the total time spent on the topic.

We similarly created an "overall composite lesson" derived from the data of all lessons on all the topics.

The next figures show the mean number of episodes per lesson in which the different mathematical foci, context and didactics were observed for the two different "composite lessons". We also performed Mann Whitney $U$-test to determine the specific influences of the topic [2].

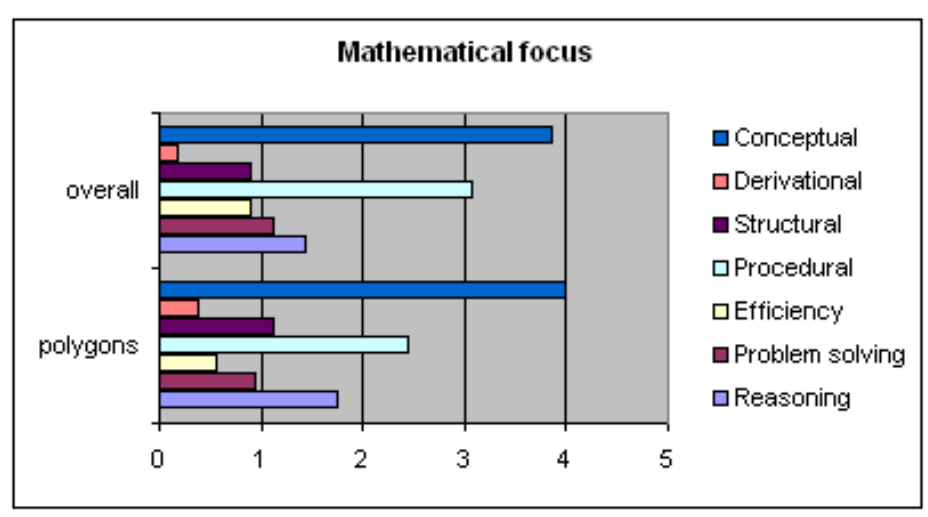




$$
\text { "szeredi" — 2007/8/9 — 14:01 — page } 44-\# 16
$$

The Mann-Whitney $U$-test shows that in secondary polygon lessons the number of episodes with efficiency and procedural work is significantly lower than the mean.

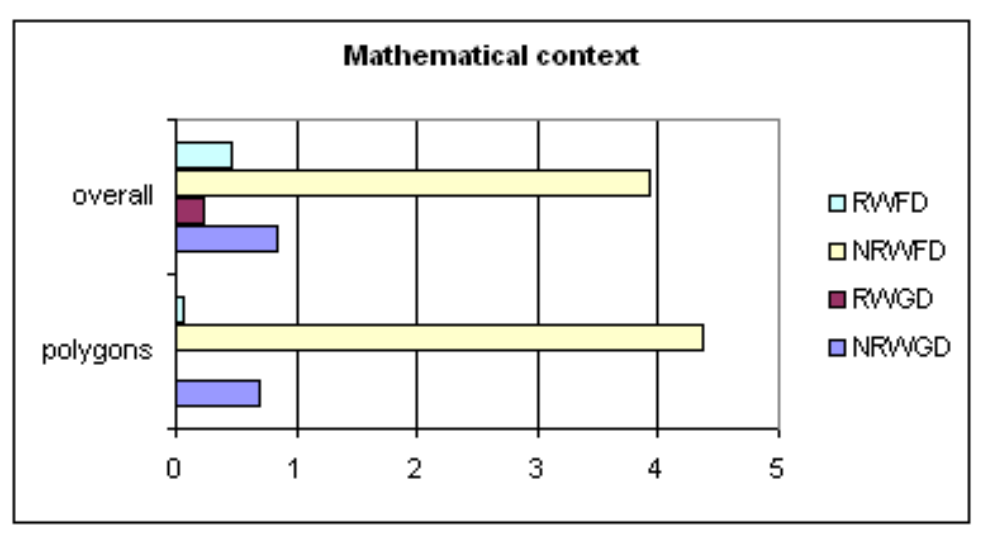

The Mann-Whitney $U$-test shows that in secondary polygon lessons the number of episodes with real world fabricated data is significantly lower than the mean.

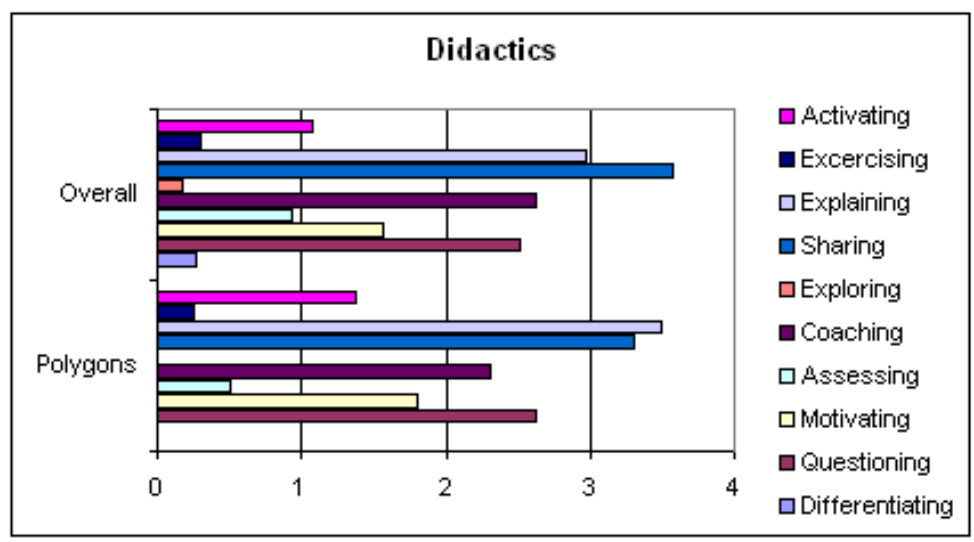

The Mann-Whitney $U$-test shows that in secondary polygon lessons the number of episodes with assessing is significantly lower while with differentiating is significantly higher than the mean.

The next two figures show the comparison of pedagogical and social activities of the two types of composite lesson: 


$$
\text { "szeredi" — 2007/8/9 — 14:01 — page } 45-\# 17
$$

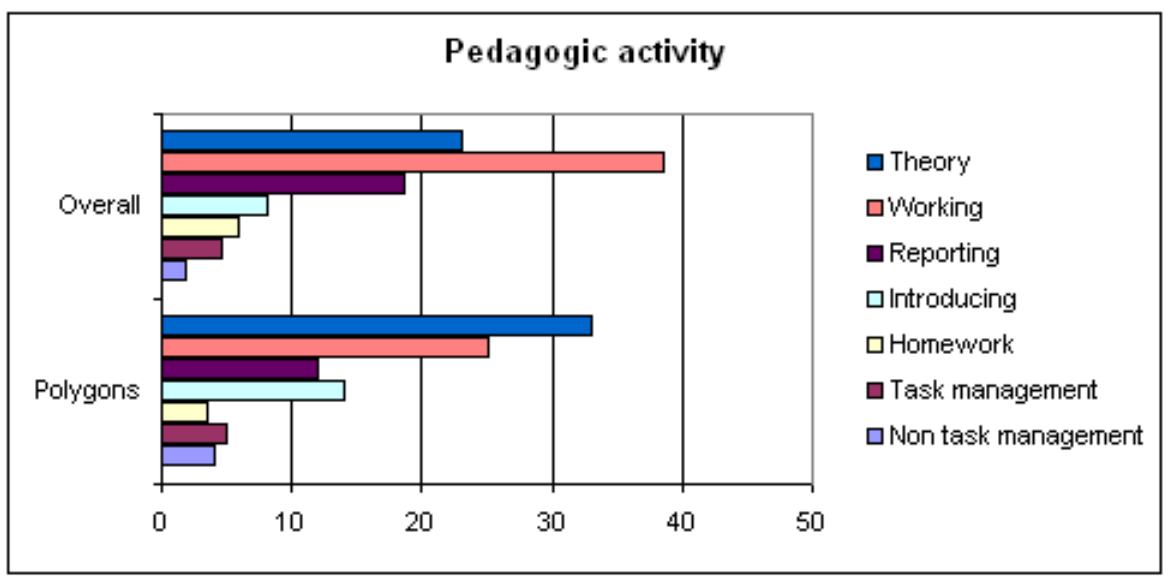

The Mann-Whitney $U$-test shows that in secondary polygon lessons significantly more time was spent on theory, working on problems, introducing a problem or activity while significantly less time on reporting solutions than the mean.

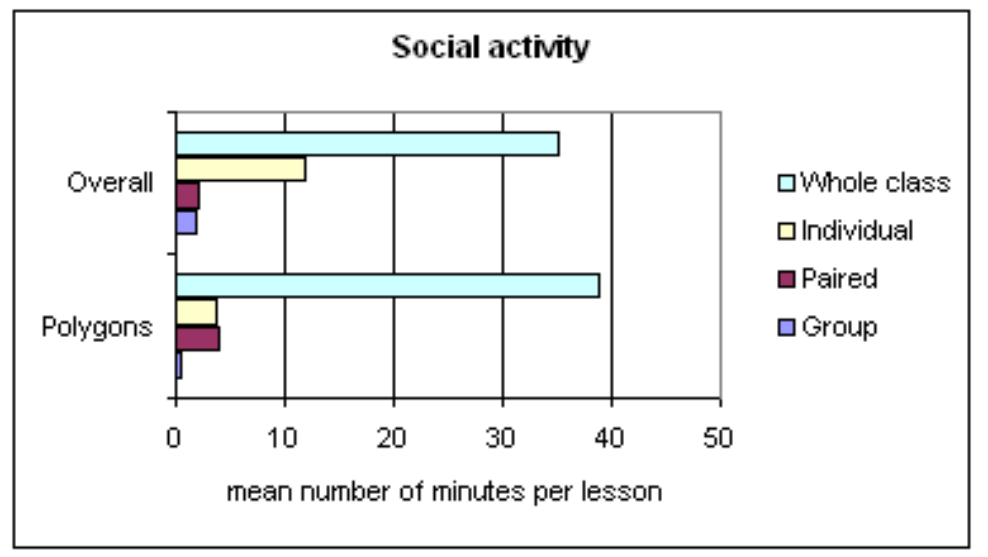

The Mann-Whitney $U$-test shows that in polygon lessons significantly less time was spent on individual activities than the mean. 


$$
\text { "szeredi" — 2007/8/9 — 14:01 — page } 46 \text { — \#18 }
$$

\subsection{Analysis of the objectives}

Let us see now how the general aims listed in our theoretical framework [15] can be realized in the topic of secondary polygons and how they were realized in the investigated geometry lessons.

"To describe, understand and interpret the real world and its phenomena."

Polygons provide plenty of opportunities to connect abstract geometrical concepts with reality, and vice versa. But in our videotaped lessons not very much of these opportunities were used. We coded only one of the total 81 episodes as real word problem with fabricated data, and zero as real word problem with genuine data. However we can find some traces of referring to reality.

The English teacher explained the concept of parallel lines referring to railway lines; the Hungarian teacher gave a quite fabricated problem about a bicycle tour with two algebraic soolutions, but at the end the students realized that one of the solutions can not occur in reality; the Spanish teacher gave a problem about a window, and with the help of the Pythagorean Theorem they found that it cannot be rectangular.

Furthermore these lessons served the above aim in many indirect ways.

"To supply an example of axiomatic theory."

This aim is too early and cannot be fulfilled at this age.

"To provide a rich and varied collection of problems and exercises for individual student activity."

Polygons are good sources for that. They are easy to analyze, it is easy to find interesting properties about them, analogies and relationships between them.

The data shows that quite a lot of problems and exercises were brought into the classroom, but most of the time not for individual work.

The richness and variedness of these problems is more questionable. The collected data shows, that quite a lot of the problem solving is procedural and exploring scored 0 of 81 . The content of the lessons shows that a lot of time is spent on naming and signing. It is in accordance with Clemens and Battista who claim that "the major focus of standard elementary and middle school curricula is on recognizing and naming different types of polygons using proper symbolism for simple geometric concepts, developing skills with measurement and construction tools such as a compass and protractor, using formulas in geometric measurement" [5]. Besides we could see quite a lot of positive examples as well. 


$$
\text { "szeredi" — 2007/8/9 — 14:01 — page } 47 \text { — \#19 }
$$

The Spanish teacher made an electronic book for the children with varied problems - some of them appropriate for investigation as well. The Hungarian teacher offered a rich collection of problems on several levels. However, both teachers left little opportunity for individual student activity. The English lesson contained less problem solving but the teacher left more space for the students.

"To train learners to make guesses, state conjectures, provide proofs and find out examples and counterexamples."

There are quite a few simple theorems about polygons which can be used for developing the need and ability of deductive reasoning of the students. Polygons are one of the richest areas in school curriculum to serve the aim stated above. This richness was very poorly exploited in the lessons. Derivational episodes occurred only in Belgian and Hungarian lessons, altogether only 6 from the 81 . We can find much more episodes with reasoning (28 from 81 ) but very few of them can be connected to stating conjectures and providing proofs.

The Spanish teacher brought in the Pythagorean Theorem but it was stated and proven by him based on the electronic book. In one of the English lessons the children made a conjecture (a regular shape must have parallel sides) and they investigated it until a counterexample (regular triangle) was found. We can find the highest number of episodes with reasoning in the Hungarian lessons but it meant mostly one-step deduction.

"To serve as a tool for other areas of mathematics."

For that purpose there are many possibilities in the area of polygons inside and outside geometry as well. That seems to be in accordance with the statistics, which shows a bit more structural episodes - but not significantly more - than the mean.

The Belgian teacher moved on from polygons to cubes and cuboids; from calculating area to calculating surface area and volume. The Spanish teacher introduced the Pythagorean Theorem and applied it for quadrilaterals. The Hungarian teacher offered some problems leading to other areas of mathematics (combinatorics, number theory) e.g. by investigating the possible angles of regular polygons they got to some divisibility questions.

Naturally during these lessons they developed many tools they may use later.

"To enrich the public perception of mathematics."

All four teachers intended to give useful tools to the students and to motivate them in different ways (using computers, manipulatives, games etc.), but we can 


$$
\text { "szeredi" — 2007/8/9 — 14:01 — page } 48 \text { — \#20 }
$$

not determine how the students' perception of mathematics was influenced by the observed lessons.

\subsection{Analysis of conceptual aspects}

\section{Definitions and properties}

Many general concepts of geometry belong to the topic of polygons, which are basic elements of the "verbal vocabulary" of geometry. For example side, angle, vertex, diagonal, parallel lines, perpendicular lines, equal segments, equal angles, bisector...

Our data shows that a great emphasis was put on theory or conceptual development (33\% of the time) and focusing on concepts (64 episodes of 81 ). In spite of this the teachers (and the children) did not make distinction between definitions and properties in most of the cases. In many cases the emphasis was on naming and notation. They missed the opportunity to use symmetries for defining special polygons. Teaching of properties was quite often based either on repetition or on visual prototypes. We can find some examples of both proper and improper definitions.

In one of the Belgian lessons the teacher encourages the students to modify the definition of the diagonal of a quadrilateral in order to get a more general definition of a diagonal of a polygon. At another occasion she defined the "height" of cuboids as the length of its longest vertex.

\section{Classification}

Different sorts of classifications of polygons give good opportunities to learn more about sets and to develop children's logical thinking as well. Hungarian students were already familiar with the different kinds of polygons, while the Spanish lessons were mostly about triangles where classification is not a problem. In the other classes there were more new pieces of knowledge to learn and classification was a more difficult question for them. None of the teachers used Wenn diagrams to illustrate the classification of polygons but we could see some examples of clarifying the logic connections.

The Belgian teacher asked a series of questions like "Is a parallelogram a rhomb? Is a rhomb a parallelogram? ... If I would draw a parallelogram with four right angles what kind of figure would that be? ..."

In one of the English lessons while solving a problem a rhombus proves to be a square which allows the teacher to introduce the idea that a square is also a rhombus. However, the teacher does not go into this deeper with that low ability 


$$
\text { "szeredi" — 2007/8/9 - 14:01 — page } 49-\# 21
$$

group. Later she plays an "I like" game in which the logic connections play important role and the ideas of inclusive sets and hierarchical connections are indirectly present.

\section{Symmetries}

Symmetries can be very useful tools for investigating the properties of special polygons.

While children work with symmetrical shapes, they can get used to looking for corresponding details: corresponding angles, sides, vertices, arcs, areas, polygons, etc. Symmetrical objects, photos, cut outs can be used for that purpose, together with the abstract drawings of geometrical shapes, like polygons, circles... This possibility was very poorly exploited. Looking for equal sides and angles was an important task in each of the classrooms but most of these were not connected to the symmetry of the shape. Questions about symmetry occurred only in the English and the Hungarian lessons, but symmetry was more like another piece of knowledge than a tool.

\section{Proofs}

In the observed lessons the students mainly worked on van Hiele Level 1. There were examples of working on Level 2 and level 0, as well, but no examples of children working on higher levels.

De Villiers (1994) concurs that deductive reasoning first occurs at van Hiele Level 3., and Senk (1989) investigations show that van Hiele Level 4. is the level at which students master proof, with Level 3 being a transitional level [5].

We could see examples for informal deduction, justifying and reasoning mostly as an answer to the teacher's question - but very little traces of doubts, debates, questions raised by children, of intentions to convince each other or of curiosity. Apparently children accepted several facts about polygons but we do not know how much they are really convinced and can use them as starting points of proofs.

\section{Drawings (visual images)}

In establishing truth, the drawings play a special and important role; they are some sort of mediators between reality and mathematics. So if properly used, they provide a rich field "to describe, understand and interpret the real world and its phenomena" which was the first on the list of aims in the ICMI Study of Villani et al. (1996). 


$$
\text { "szeredi" — 2007/8/9 — 14:01 — page } 50 \text { — \#22 }
$$

Drawings occurred in every lesson but in some cases were not properly used. For example, a frequently used exercise is to recognize shapes from drawings with some parallel looking sides and/or some equal looking sides and/or with some angles which look right angles. This kind of exercise does not tell explicitly anything about the intention of the drawer, so in fact the children are expected to work on the 0 . visual level, where the shapes are judged by their appearance. In one of the lessons the children were encouraged to get the answer by measuring. Measuring does not help in these cases, because you cannot know whether a $1 \mathrm{~mm}$ difference is due to the incorrect measurment or it was the intention of the drawer. Drawing and measuring can be very useful when getting to conjectures, but not as a basis for proof.

All the teachers except the Spanish one positioned the shapes most of the time in standard position.

\subsection{Analysis of the didactic tools}

The four teachers chose different ways of structuring the content. They used different didactic tools to help effective learning. Some of the differences came from the different personalities of the teachers, but some of them were characteristic for a country in all of the four topics.

The English teacher covered relatively small content area but approached it in many different ways. She wanted to provide a sound base for studying polygons (mainly quadrilaterals), she put the main emphasis on the identification of different types of polygons and worked in details with notions like parallel or right angle lines, equal sides and angles and the signing and naming of them. She did not try to relate the topic to previous knowledge and even when a good opportunity aroused she avoided clarifying the deeper connections.

To motivate the children and to provide a better understanding she used a rich variety of methods, like games, realistic approaches, worksheet, white board, linguistic questions. Without pressing the students she created a friendly atmosphere and they took an active part in the lesson.

It was a low ability class, what may have been the reason of the small number of episodes with reasoning and problem solving.

The Belgian teacher also put a big emphasis on naming and signing but she covered a much bigger curriculum area. The content of her lessons was strongly structured; she tried to make connections between the existing knowledge and the new topic and used analogies to build up new concepts and definitions. She 


$$
\text { "szeredi" — 2007/8/9 - 14:01 — page } 51 \text { — \#23 }
$$

started with reviewing the names and some properties of special quadrilaterals. Next she introduced the concept of the bisector of a segment, the bisector of an angle and their construction. Applied these new concepts for quadrilaterals and then moved from questions about the area of polygons towards analogue spatial problems, like the surface area and the volume of a cuboid.

The main type of social activities was working in whole class with a lot of questioning and sharing, although most of her questions required only one word answers.

She made little effort to motivate the children and reasoning played minor role during her lessons. In spite of her frequent questions and the pressure she put on the children they remained quite passive.

The Hungarian teacher constructed a series of miscellaneous problems (some of them quite complex) to review and apply previous knowledge about polygons and the Pythagorean Theorem. Besides practising and developing their problem solving skills, he tried to give a more general picture about geometry and to make connections with real life and other areas of mathematics, like combinatorics and number theory. He put the main emphasis on revising prior knowledge, applying it in problem solving and creating connections between different areas of mathematics. He used various methods of motivation, like games, display materials and a lot of questioning, sharing and explaining. Similarly to the Belgian teacher he strongly directed the work of the students but at the same time he created a vivid, competitive atmosphere.

It was a good ability class, with children one year older then the others, where reasoning was a natural part of most of the episodes.

The Spanish teacher made efforts to cover a broad curriculum area with the help of a rich and interesting teaching material. He followed the structure of an electronic textbook, written by him. The electronic textbook contained not only theory and exercises but opportunities of experimenting and demonstration of proofs as well. The content of the E-book was thoroughly structured. At the same time the lessons were rather unstructured. While displaying the content of the E-book he explained the usage of the E-book and the usage of CABRI at the same time. This way he left little opportunity for individual discovery. The main tool of motivation was using teaching software. Unfortunately the children could not concentrate on the mathematics, all their questions were connected to problems with the computer, and this way at the end the lessons were much more about the usage of the software than about geometry. 


\section{Theoretical/educational significance}

The main significance of the project lies in the collection of videotaped lessons which show different approaches of important mathematic concepts and their teaching while the statistical data we collected enhances the usefulness of the video-taped material. They can give a deeper insight into and a better understanding of both the theory of teaching polygons and the teaching practice of these countries. We believe that the results of the study can be used by educators from the non-participating countries, as well.

Our findings can be relevant for curriculum and textbook developers, as well as for teacher trainers. They can be very effectively used in both pre-service and in-service training.

In the case of Hungary the complete lack of exploration, differentiation, real world problems and group work warns us to put a greater emphasis on implementing these types of didactic tools in the teaching practice, while not giving up traditions like using the didactic tools of questioning and sharing, and strictly structuring the content of mathematics teaching. 


$$
\text { "szeredi" — 2007/8/9 - 14:01 — page } 53 \text { - \#25 }
$$

\section{Appendix I.}

Short description of the schools and lessons

$$
\text { Belgium - Flanders }
$$

The lessons about polygons were videotaped in the seventh grade of the 'Paridaensinstituut'. The school already organizes education at the primary and the secondary level for about 200 years and is situated in Leuven, a middle-sized city in Flanders. The number of students of the secondary school amounts to approximately 650 and the school is more selective than comprehensive. It is selective in the sense that students are following clearly distinctive tracks. The smarter students take the Latin track and the others follow the humanities track. We videotaped our five lessons in a humanities class.

The teacher is approximately fifty years old and has a lot of teaching experience regarding mathematics in secondary schools. The mixed-ability class involves 24 students; their socio-economic status is middle to high.

The five lessons were videotaped on two days in mid November: three lessons on Tuesday (two in the morning and one in the afternoon) and two lessons on Friday morning. The lessons lasted approximately fifty minutes.

\section{$1^{\text {st }}$ lesson: Characteristics of quadrilaterals}

Starts with a managerial episode.

Revision about some special types of quadrilaterals and the characteristics of those.

A short period of seatwork follows in which different children have to draw, different quadrilaterals. The teacher checks the results.

Discussion about isosceles trapezium which was new for the students.

Some students draw their figures at the blackboard while all students draw all quadrilaterals on their sheet. Long period of class discussion about the characteristics of all kind of quadrilaterals.

The teacher explains first the usage of some symbols. Then students respond to successive questions in order to mark all quadrilaterals with the symbols of equal sides and right angles.

Finally the students finish drawing all figures (with their symbols) that are at the blackboard on their paper.

\section{$2^{\text {nd }}$ lesson: Classification of quadrilaterals}

First the students have to define different quadrilaterals drawn on the blackboard and indicate symbols on figures. 


$$
\text { "szeredi" — 2007/8/9 - 14:01 — page } 54 \text { — \#26 }
$$

The teacher explains how students can name plane figures by marking the vertices with capital letters. The teacher emphasizes the relationship between different quadrilaterals.

After that in connection with a question of a student the teacher asks questions about the relation between different quadrilaterals. During a series of quick questions and answers the students get insight in the relationship between the quadrilaterals, while sometimes the teacher explains some concepts by her own.

The lesson ends with a short summary and completion of the last two lessons (cf. worksheet).

\section{$3^{\text {rd }}$ lesson: Angles, perpendicular bisectors and bisectors of angles}

Starts with filling in agenda and instructions for homework.

Revision of the concepts of the previous lesson, many questions with short answers, occasional explanations of the teacher.

Next they learn to measure angles. The teacher tries to get some learner-input about some new concepts as well.

Short individual work follows, students measure the angles they drew.

Next they deal with the perpendicular bisector of a line segment and the bisector of an angle.

Revision of all kind of definitions. The teacher poses successive number of questions to refine some of those definitions which are not exact enough.

The last part concerns measuring the perimeter of different quadrilaterals. After that measuring the surface of the quadrilaterals drawn on squared paper during the first lesson.

\section{$4^{\text {th }}$ lesson: Characteristics of quadrilaterals and their diagonals}

Starts with revision of the previous lesson (not video-taped). Questions about the procedure to construct a perpendicular bisector of a line segment and of an angle.

Homework giving and distribution of new worksheets follow.

They solve together an exercise about the names of quadrilaterals. Then some questions follow about the different parts of a cuboid to explain the difference between the symbol ' $\mathrm{H}$ ' and the symbol ' $\mathrm{h}$ '. They return to the quadrilaterals to indicate all kind of symbols. A lot of questions follow and the answers should be justified.

This activity is stopped for a more theoretical topic about diagonals.

After that the students work on diagonals.

$5^{\text {th }}$ lesson: Perimeter and area of quadrilaterals, cubes and cuboids 


$$
\text { "szeredi" — 2007/8/9 - 14:01 — page 55 — \#27 }
$$

Starts with an activity about the unfoldings of a cube and a cuboid. Students have to indicate the height, the length and the width on unfoldings. By questions and answers revise the area of the square.

While the students are measuring, the teacher asks why the unity of area is to the second power and the unity of volume is to the third power. They discuss the question.

After that, the students report their measurement, and the teacher derives the formula of the surface area of a cube and a cuboid by interaction with the students.

Next the students in pairs measure the height, length and width of solids and plane figures and complete formulae of area and surface. Meanwhile the teacher helps some students. Sometimes she explains things to the class.

After a short revision the teacher reflects on a question about usage of brackets and gives instructions for the homework.

\section{England}

The English secondary polygon lessons were videotaped in an year 8 class in Stockport School which is a 11 to 16 comprehensive school in Stockport, one of the towns which make up the Greater Manchester area. It is situated just outside the centre of the town. The school has about 1000 pupils who come from a wide range of social backgrounds and are of all abilities. The measure usually used in England to express the social status of the pupils is the percentage of the pupils who are eligible for free school meals. Stockport school has $13 \%$ of its pupils claiming free school meals. It can thus be seen that a significant percentage of the pupils come from a disadvantaged background. It is a popular school in which the numbers are growing.

The class shown in this video is one of the lowest ability sets in year 8 . There are 25 pupils in the class.

The teacher has about five years teaching experience, all in this school. She trained on the two year post graduate certificate in education which is open to graduates in disciplines cognate to mathematics and is characterized by the fact that the students are taught mathematics by mathematics educators rather then mathematicians.

The three lessons were videotaped during one week near the beginning of the school year.

The lessons were on Monday morning, Tuesday afternoon and Thursday morning. Each lesson lasted 50 minutes. 


$$
\text { "szeredi" — 2007/8/9 - 14:01 — page } 56 \text { - \#28 }
$$

$1^{\text {st }}$ lesson: Parallels, perpendiculars, equal sides and right angles in quadrilaterals

Starts with a revision on triangles. Discussion on the meaning of "tri" in words and on marking equal sides and angles.

Work on the definition of parallel and on how to mark parallel lines.

Selection and marking of parallel lines on diagrams. Outcomes are discussed and the definition of parallel is emphasized.

Establishing the meaning of perpendicular and marking right angles, in a similar way, then the teacher gives them a small sheet showing how parallel and perpendicular lines and equal lengths should be marked. Worksheet showing six standard quadrilaterals on which the pupils have to mark parallels, equal sides, right angles and the name of the shape.

After some minutes pupils report on their work. At the end the pupils clear up their equipment and answer a few questions.

\section{$2^{\text {nd }}$ lesson: Types and properties of special quadrilaterals}

Starts with looking back at the sheet about the names of the different quadrilaterals and their properties. Questions to remind students what was done with an emphasis on the language and on marking.

Various tasks follow, pupils' answers on individual whiteboards.

Next the pupils work on a sheet in which two sides of a specified quadrilateral are given and they have to draw in the other two sides.

Pupils report back by drawing the shapes required on an image of the sheet projected onto the whiteboard. The teacher spends quite long periods of time helping particular pupils come to terms with some of the problems.

In the final part of the lesson they play an "I like" game.

\section{$3^{\text {rd }}$ lesson: Polygons}

Moving on with the vocabulary to polygons with more sides. Then discussing if a regular shape always have parallel sides or not.

Regular polygons and their names are discussed next. Some of the definitions are left for later work and researching their meanings is homework.

The word polygon is introduced. They discuss the difference between regular and irregular polygons for a pair of pentagons while revising the use of the word parallel and the meaning of regular.

Next problems are about axes of symmetry of a regular pentagon and two hexagons. The next task is to draw the lines of symmetry for various polygons and summarize the results. Then the pupils report back. 


$$
\text { "szeredi" — 2007/8/9 - 14:01 — page } 57 \text { — \#29 }
$$

Finally homework is set and the equipment is put away. The lesson ends with simple geometrical questions to earn the right to go.

\section{Hungary}

The name of the school where the Hungarian secondary lessons on polygons were videotaped is "Árpád Gimnázium" (Arpad secondary school). It is located on the "Buda" side of the Danube in the $3^{\text {rd }}$ district of Budapest - a part which was an ancient Roman city; and it can be reached by several type of public transportations.

The school is a state school. Because of its hundred year old traditions of the institution it also takes children from outside the district. The children come from all sorts of families with parents from all type of educational background.

There are 430 children and 57 teachers in the school.

Two classes run from grade 7 to 12 . One is specialized in the language (English and German). The other is a special mathematics class. There is also a class (from grade 9 to 12 ) which is specialized in nature sciences.

The group where the videos were taken is the half of a grade 8 mixed ability class (18 students).

The teacher has been teaching in secondary school for 18 years (starting in a school for 14 to 18 year old children which later changed for 10 to 18 year old). Now he teaches in a school for 12 to 18 year old children.

The topic just followed a series of lessons on Pythagorean Theorem and its applications. It was a summary of everything students had already learnt about polygons. It was also a part of preparation for entrance examination of gymnazia.

All the lessons were taken in the mornings and each of them lasted 45 minutes.

\section{$1^{\text {st }}$ lesson: Triangles}

Starts with evaluating last tests.

General discussion about geometry, what are the main areas of it, what are its main questions, methods.

Two combinatorical questions follow connected to some basic concepts of geometry. Emphasis is on the concepts, and on taking into account all of the possibilities. Teacher leads the investigation with his questions, and summarizes the children's answers.

Revision about triangles by playing a game. The students have to make general statements about triangles, which are true for each triangle without condition. 


$$
\text { "szeredi" — 2007/8/9 - 14:01 — page } 58 \text { — \#30 }
$$

At the end they apply their recently revised knowledge on a quite complex text problem about a bicycle tour, which surrounds a triangle and contains some algebraic constraints as well.

The lesson finishes with homework giving.

\section{$2^{\text {nd }}$ lesson: Symmetrical triangles and quadrilaterals}

After checking homework they finish the problem left open previously.

Then quick overview of the types and characteristics of symmetrical triangles using model triangles cut out of cardboard. After that the teacher builds quadrilaterals putting together two of these model triangles in many different ways. $\mathrm{He}$ asks the children to give the definition and true statements about the shapes he builds.

Teacher introduces a complex problem about a series of growing trapeziums built up of similar, right angle, isosceles triangles. The first question is about the area of these trapeziums, if the area of the smallest triangle is given. The solution and further investigations are postponed for the next lesson.

\section{$3^{\text {rd }}$ lesson: Area of polygons}

Starts with working on the question left open.

Another non-routine problem follows about the area of a pentagon built from the same set of triangles. Easier tasks come about the area of pentagons which look like little houses.

Then they collect as many formulae for calculating the area of polygons as they can and they discuss the connections between them. The teacher asks for the reasons behind. Meanwhile they revise the relationship between different types of quadrilaterals.

Next task is to calculate the area of a square if the length of the diagonal is given. The teacher asks for a quick way and some children find out, that if they look at the square as a rhombus then they can calculate the area straight of the length of the diagonal.

The lesson ends with giving homework.

\section{$4^{\text {th }}$ lesson: Polygons with more sides}

Starts with checking one question of homework.

An assessing period follows.

Then they solve together a problem about the area and the perimeter of a trapezium. Next they analyze a table in their textbook, which contains the number of vertices and the number of diagonals of 3-, 4-, 5-, 6-, $\ldots$ and $n$-sided polygons. 


$$
\text { "szeredi" — 2007/8/9 - 14:01 — page } 59 \text { - \#31 }
$$

Next discussion is about regular polygons and their angles, which involves some divisibility considerations.

Next the teacher introduces a new problem by folding an octagon from a piece of paper and the task is to decide if it is regular in mathematical sense or not. The next question is its perimeter, but it is left for homework and the lesson finishes with giving more homework.

\section{Spain}

The Institute of Secondary Teaching (I.E.S) Juan de Mairena, is found in Mairena del Aljarafe, a village situated some ten kilometres from Sevilla (in Andalucia). The four obligatory years of secondary education and the two Bachillerato years and a module of occupational training are taught here.

The centre's students come from nearby zones with quite different social backgrounds.

The building where the centre is situated dates from the early nineties having undergone three expansions due to the increase of the population in adjacent zones.

The teacher started his teaching work at the age of 17 in a Free Adopted School: these were centers created in the sixties as extensions of secondary schools in certain villages where, because of their population, the installation of a secondary school was not viable. He became a teacher with a Bachillerato. After passing the entrance test to work as a public sector teacher, he started to give classes when he was 23 years old as a mathematics teacher for 12 to 14 year-old students. He went on to secondary teaching in 1997 and since that moment has given mathematics classes in Juan de Mairena Secondary School. He has carried out many activities related to teaching.

The first year group of Obligatory Secondary Education (ESO) is made up of 29 students. It is a mixed ability class. When the teacher sets groupwork, he forms heterogeneous groups.

The topic dealt with in the four recorded sessions is on triangles, which is framed within the unit on polygons. The recordings cover the time dedicated to triangles except for the last session in the classroom dedicated to the solving of problems related to Pythagorean Theorem (which is not recorded). The unit on polygons will be extended over time, perhaps until the end of the school year (with contents distinct from triangles). 


$$
\text { "szeredi" — 2007/8/9 — 14:01 — page } 60 \text { — \#32 }
$$

$1^{\text {st }}$ lesson: Construction of triangles, familiarization with the program Cabri

PowerPoint presentation on polygons. Teacher revises the classification of triangles. He explains how to work with the electronic book.

First the students have to construct triangles.

The students work on their computers in pairs. Teacher answers questions which are technical as well as about how to do the tasks.

Instructions about finishing the task at home.

Management of the program Cabri follows. After a brief introduction through an example, the students work in pairs on activities like:

- Constructing a point.

- Constructing a straight line.

- Constructing a segment.

- Constructing an angle.

The teacher goes around the class helping the students. At the end he asks them to finish these exercises as homework and explains how to install the program at home.

\section{$2^{\text {nd }}$ lesson: Pythagorean Theorem; points and important straight lines} of a triangle

Teacher's explanation of the coming work. Powerpoint presentation on Pythagorean Theorem and some examples about its applications.

Teacher explains the activities of the electronic book about triangles and Pythagorean Theorem.

These are manipulative tasks, mainly about checking geometric properties.

Setting activities for home with Cabri without being explicit about these activities. Next working in pairs on the electronic book. The teacher dedicates himself to, firstly, solving technical problems and, secondly, to make it clear how to do the tasks.

At the end he asks them to do what was left over as homework, and gives them some more explanations for working with Cabri.

\section{$3^{\text {rd }}$ lesson: The right triangle, Pythagoras Theorem and its applications}

Start again with PowerPoint presentation. Quickly revises some properties of right triangles and proofs and applications of Pythagorean Theorem.

Then the task is set from the electronic book. 


$$
\text { "szeredi" — 2007/8/9 — 14:01 — page 61 — \#33 }
$$

Students are disorientated so the teacher decides to carry out some activities together. Discuss if a triangle, which fulfils Pythagorean Theorem, has its sides multiplied by a number, continues to fulfill the theorem or not. Then they look for the connection between the algebraic and the verbal expression of Pythagorean Theorem, asking them for the meaning of both.

The last activity consists of testing Pythagorean Theorem based on the different decompositions of a square.

To finish he asks the students to construct a right triangle using Cabri as homework.

$4^{\text {th }}$ lesson: Points and important straight lines of the triangle using Cabri

Starts with explanation of the task in which they are using Cabri, to construct and label geometric figures: point, straight line, segment, triangle, perpendicular bisectors. Then build the altitudes, bisectors and medians and corresponding points. The teacher shows everything on the projector, then students work in pairs.

The teacher continues helping them sometimes interrupts the activity with explanations for the whole group. He deals in details with the circumcentre of different types of triangles.

The teacher asks the students that once they have constructed each important point, that they manipulate the triangle, ask questions and come to conclusions.

Finally the teacher talks about the next session. 


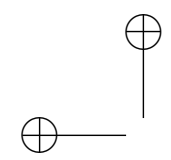

$$
\text { "szeredi" - 2007/8/9 - 14:01 - page } 62-\# 34
$$

Appendix II.

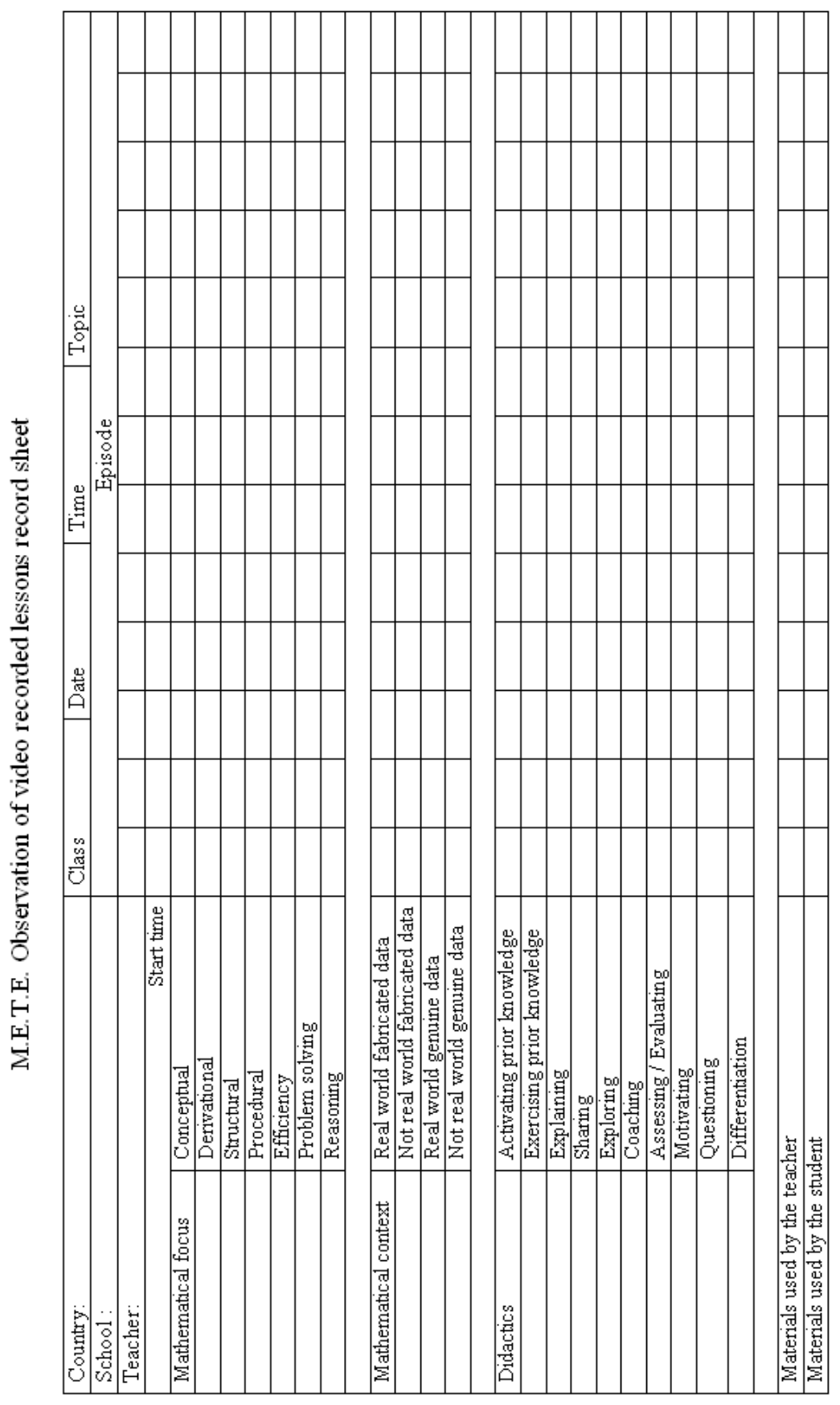


Appendix III.

\section{M.E.T.E. summary sheet for video recor ded lessons}

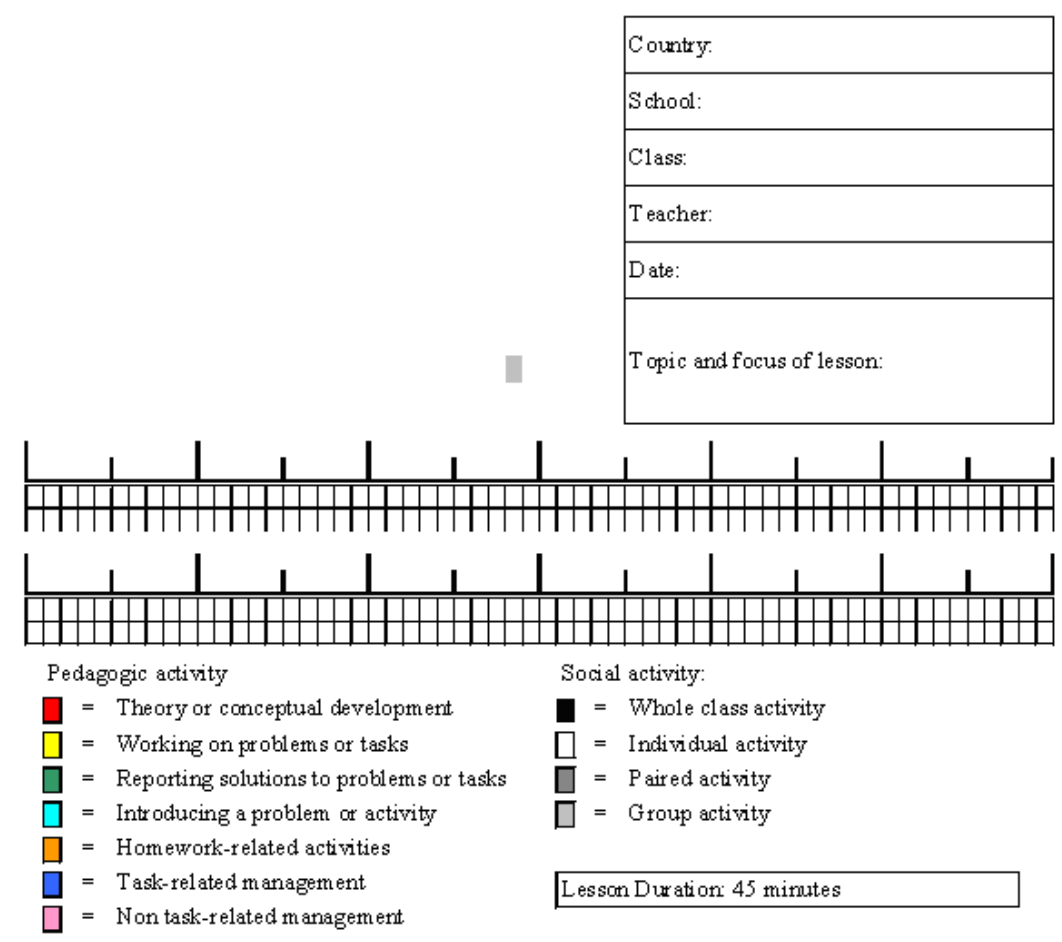

Key words or special features: 


$$
\text { "szeredi" — 2007/8/9 — 14:01 — page } 64 \text { — \#36 }
$$

\section{References}

[1] P. Andrews, J. Carillo, N. Clement, E. De Corte, F. Depaepe, K. Fried, G. Hatch, G. Malaty, P. Op't Eynde, S. Pálfalvi, J. Sayers, T. Sorvali, É. Szeredi, J. Török, L. Verschaffel, International comparisons of mathematics teaching: searching for consensus in describing opportunities for learning, Paper presented to discussion group 11 , international comparisons of mathematics education, of the $10^{\text {th }}$ International Congress on Mathematics Education (ICME-10), Copenhagen, Denmark, 2004.

[2] P. Andrews, Mathematics Education Traditions of Europe (METE) project: Methodological perspectives and instrument development, Paper presented in a Symposium on "The Mathematics Education Traditions of Europe (METE) project: Principles and outcomes" at the $11^{\text {th }}$ Biennial EARLI Conference, Nicosia, Cyprus, August 23-27, 2005.

[3] P. Andrews, G. Hatch and J. Sayers, "What do teachers of mathematics teach? An initial episodic analysis of four European traditions", in: Proceedings of the sixth British Congress of Mathematics Education, held at the University of Warwick, (D. Hewitt and A. Noyes, eds.), 2005, 9-16.

[4] C. Alsina et al., Invitación a la Didáctica de la Geometría, Síntesis, Madrid, 1987.

[5] D. H. Clements and M. T. Battista, Geometry and spatial reasoning, in: Handbook of Research on Mathematics Teaching and Learning, (D. A. Grouws, ed.), NCTM \& Macmillan, New York, 1992.

[6] J. Carrillo et al., Report of the analysis of the Teaching of Polygons in Primary School, 2004, Unpublished.

[7] M. De Villiers, The role of a hierarchical classification of quadrilaterals, For the Learning of Mathematics, 1994.

[8] D. Fuys, D. Geddes and R. Tischer, English translation os selected writings of Dina van Hiele-Gedolf and Pierre M. van Hiele, ERIC, Columbus, OH, 1984, ED 287697.

[9] R. Hershkowitz, B. Parzysz and J. van Dormolen, Space and Shape, in: International Handbook of Mathematics Education, (A. J. Bishop, K. Clements, C. Keitel, J. Kilpatrick and C. Laborde, eds.), Kluwer Academic Publishers, Dordrecht, The Netherlands, 1996.

[10] C. S. Kay, Is a spuare a rectangle? The development of first grade students understanding of quadrilaterals with implications for the van Hiele theory of the development of geometric thought, Dissertations Abstracts International. 47. 2934A (university Microfilms No. DA8626590), 1987.

[11] J. Piaget, Judgement and reasoning in the child, Harcourt, Brace and Co., New York, 1928.

[12] G. Pólya, Mathematical discovery. On Understanding, Learning, and Teaching Problem Solving, John Wiley and Sons, Inc., New York, 1962.

[13] S. I. Senk, Van Hiele levels and achievement in writing geometriy proofs, Journal for Research in Mathematics Education 20, 1989, 309-521.

[14] J. Török, The METE Project, Teaching Mathematics and Computer Science 4, no. 2, Institute of Mathematics, University of Debrecen, 2006, 353-364. 


$$
\text { "szeredi" — 2007/8/9 — 14:01 — page 65 — \#37 }
$$

[15] V. Villani et al., Perspectives on the teaching of geometry fo the $21^{\text {st }}$ century, Discussion Document for an ICMI study. The International Commission on Mathematical Instruction, 1996.

[16] I. Wirszup, Breathroughs in the pssychology of learning and teaching geometry, In J. I., 1976.

[17] Martin and D. A. Bradbard, Space and geometry, Papers from a research workshop, Athens, GA University of Georgia, Georgia Center for the Study of Learning and Teaching Mathematics. (ERIC Document Reproduction Service No. ED132033).

ÉVA SZEREDI and JUDIT TÖRÖK

DEPARTMENT OF MATHEMATICS TEACHER TRAINING

EÖTVÖS LORÁND UNIVERSITY

H-1117 BUDAPEST

PÁZMÁNY PÉTER SÉTÁNY 1/C

HUNGARY

PHONE: (00) 36-1-2090555/864

E-mail: eszeredi@gmail.com

E-mail: t.jutka@gmail.com

(Received February, 2006) 